\title{
Effective Treatment of Acne Fulminans with Oral Corticosteroids
}

\author{
Ichiro Kurokawa \\ Department of Dermatology, Meiwa Hospital, Nishinomiya, Japan \\ Email: kurokawa.i@meiwa-hospital.com
}

How to cite this paper: Kurokawa, I. (2020) Effective Treatment of Acne Fulminans with Oral Corticosteroids. Journal of Cosmetics, Dermatological Sciences and Applications, 10, 107-109. https://doi.org/10.4236/jcdsa.2020.103012

Received: June 18, 2020

Accepted: August 25, 2020

Published: August 28, 2020

Copyright $\odot 2020$ by author(s) and Scientific Research Publishing Inc. This work is licensed under the Creative Commons Attribution International License (CC BY 4.0).

http://creativecommons.org/licenses/by/4.0/

\begin{abstract}
An 18-year-old man had numerous multiple painful nodulocystic lesions, pustules, and necrotic hemorrhagic ulcerative lesions with crusts on the face, back, chest and upper arm two weeks ago. Systemic symptoms such as fever, general fatigue and arthralgia were not observed. Laboratory findings revealed an elevated white blood cell count with a neutrophilia and C-reactive protein. Oral antimicrobials did not respond. Consequently, oral prednisolone $(20 \mathrm{mg} / \mathrm{d})$ for two weeks induced remarkable improvement promptly. A case of acne fulminans without systemic symptoms successfully treated with oral corticosteroids has been reported.
\end{abstract}

\section{Keywords}

Acne Fulminans, Treatment, Systemic Symptoms

\section{Case Report}

An 18-year-old man had inflammatory acne lesions on the face, back and upper arm two years ago. He was treated with oral cefdinir, topical antimicrobials and benzoyl peroxide (BPO) two years ago. However, the lesions did not respond to these treatments.

Numerous multiple painful nodulocystic lesions, pustules, and necrotic hemorrhagic ulcerative lesions with crusts developed the face, back, chest and upper arm two weeks ago. Systemic symptoms such as fever, general fatigue and arthralgia were not observed. Movement restriction caused by pain was observed in the shoulder joint. He was diagnosed as acne fulminans (AF). Laboratory findings revealed an elevated white blood cell (WBC) count $(20,300 / \mu l)$ (normal level: 4000 - 9000/ $\mu$ l) with a neutrophilia and C-reactive protein (CRP) (3.91 $\mathrm{mg} / \mathrm{dl}$ ) (normal level: below $0.30 \mathrm{mg} / \mathrm{dl}$ ). Notably, Staphylococcus epidermidis was detected in the bacterial culture from the lesion. 
Initially, the patient was treated with oral faropenem $600 \mathrm{mg} / \mathrm{d}$ and Saireito $8.1 \mathrm{~g} / \mathrm{d}$ (Japanese Herb) for two weeks. Subsequently, he was treated with oral minocycline $100 \mathrm{mg} / \mathrm{d}$. The lesions did not respond to these treatments and rather developed into a hemorrhagic ulcer (Figure 1(a)). Consequently, he was treated with additional oral prednisolone $(20 \mathrm{mg} / \mathrm{d})$ for two weeks. The lesions showed remarkable improvement promptly. The hemorrhagic ulcerations were re-epithelialized, resulting in postinflammatory hyperpigmentation (Figure 1(b)). In addition, the pain subsided quickly, and movement restriction in the shoulder joint was improved.

The informed consent was obtained from the patient to reproduce the clinical findings.

\section{Discussion}

$\mathrm{AF}$ is usually defined as a sudden onset severe ulcerative acne with toxic effects such as fever, weight loss and arthralgia. It fails to respond to antimicrobial therapy and shows favorable responses to debridement in combination with steroid therapy [1] [2]. AF is exclusively observed in adolescents of age ranging from 13 - 16 years [1] [2]. Notably, this condition is more frequently observed in males than in females [1] [2], and its clinical manifestation includes hemorrhagic ulcerations with pain [1] [2]. AF without systemic symptoms and abnormal laboratory findings were reported as AF "sine fulminans" [3]. In our case, a sudden onset was observed with painful hemorrhagic necrotic ulcers with crusts. Additionally, increased WBC count with neutrophilia and elevated CRP were observed. In spite of unresponsiveness by antimicrobial therapy, the lesions responded to corticosteroid therapy. In view of the above-mentioned findings, our patient was diagnosed with AF.

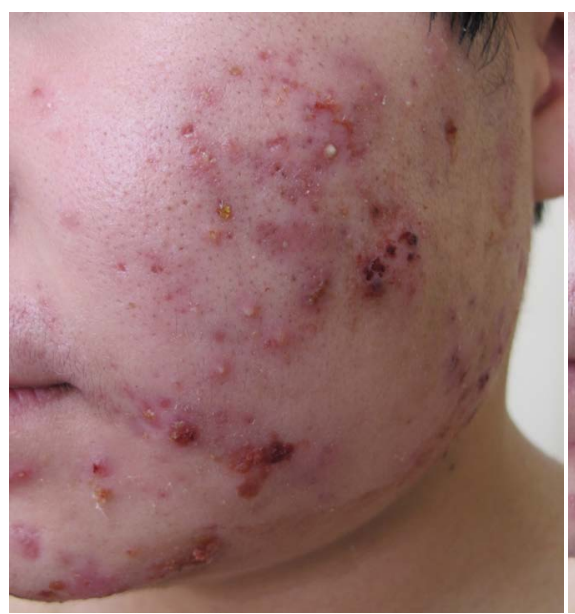

(a)

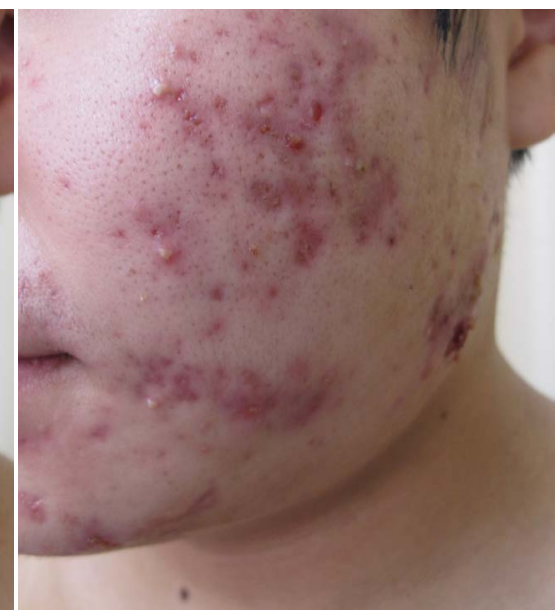

(b)

Figure 1. (a) Clinical manifestation before systemic corticosteroid treatment: hemorrhagic necrotic ulcerations with crusts, nodulocystic lesions and pustules were observed on the left face; (b) Clinical manifestation after systemic corticosteroid treatment: the hemorrhagic necrotic ulcerations with crusts were re-epithelialized, resulting in postinflammatory hyperpigmentation on the left face. Atrophic scars remained. 
The etiology of AF is unclear. The immunological response to Cutibacterium acnes ( $C$. acnes), neutrophil function, hypersensitive responses to either sebum or bacterial antigens, and genetic factors might be responsible [4].

As differential diagnosis, acne conglobata (AC) is considered. AC is usually observed in adults [4]. The clinical manifestations of AC mainly include nodules, cysts, and polyporus comedones [4].

Concerning therapy for AF, a combination therapy with corticosteroids and isotretinoin is highly recommended [1]. However, the use of isotretinoin is not allowed in Japan. Isotretinoin may precipitate AF as it promotes fragility of the sebaceous duct, resulting in significant contact with $C$. acnes [1].

The long-term prognosis of AF after the treatment is good without recurrence.

\section{Conclusion}

A case of acne fulminans without systemic symptom successfully treated with oral corticosteroids has been reported.

\section{Conflicts of Interest}

The author declares no conflicts of interest regarding the publication of this paper.

\section{References}

[1] Plewig, G. and Kligman, A.M. (2005) Acne Fulminans. In: ACNE \& ROSACEA, 3rd Edition, Springer-Verlag, Berlin, 342-351

https://doi.org/10.1007/978-3-642-59715-2_24

[2] Cunliffe, W.J. (1989) Acne Fulminans. In: ACNE, Martin Dunitz, London, 33-36.

[3] Thomson, K.F. and Cunliffe, W.J. (2000) Acne Fulminans 'Sine Fulminans'. Clinical and Experimental Dermatology, 25, 299-301. https://doi.org/10.1046/j.1365-2230.2000.00647.x

[4] Katsambas, A.D., Dessinioti, C. and Cunliffe, W.J. (2014) Clinical Aspects of Acne Fulminans. In: Pathogenesis of Acne and Rosacea, Springer, Berlin, 223-226. https://doi.org/10.1007/978-3-540-69375-8_29 